\title{
PERENCANAAN PENGGUNAAN LAHAN MELALUI PENDEKATAN PREDIKSI EROSI DAN KLASIFIKASI KEMAMPUAN LAHAN DI DAERAH ALIRAN SUNGAI KOLOH PASIRAN LOMBOK TIMUR
}

\author{
Sulastri, ${ }^{*}$ I Wayan Sandi Adnyana, ${ }^{2}$ I Nyoman Merit ${ }^{2}$ \\ 1) Program Studi Magister Ilmu Lingkungan Universitas Udayana Bali \\ ${ }^{2)}$ Fakultar Pertanian Universitas Udayana Bali \\ *Email : tri3las@yahoo.com
}

\begin{abstract}
Erosion is a form of land degradation is very serious in Koloh Pasiran watershed. This condition perceived more severe by the fact that the understanding of the process of saving the natural resources of forest, soil and water have not received maximum attention. This is evidenced by the presence of illegal logging, forest fires around the area of the watershed during the dry season and flooding during every rainy season. Therefore, the research conducted with the aim to: 1) determine the level of erosion and soil and water conservation planning in the Koloh Pasiran watershed, 2) determine the land capability class in Koloh Pasiran watershed and 3) to plan land use capability classes based on erosion rate.

Observations and sampling of soil samples for prediction of erosion, soil conservation and classification approach according, planning based on common land unit. This land unit maps obtained from the land use maps overlay by slope, soil and land use maps done by estimating the magnitude of the erosion equation USLE (Universal Soil Loss Equation) of Wischmeier and Smit (1978). Determine land capability class with land capability classification approach according Arsyad (1989). Land use planning and soil and water conservation in addition to using USLE equation also uses land capability classification according Arsyad (1989).

The results show the level of erosion prediction calculation slight to very severe erosion. Mixture of garden soil with a $2 \%$ slope erosion rates relatively slight. Dry land with a slope of $2 \%$ classified as severe erosion and the shrub land with a slope of 2-3\% erosion classified as severe to very severe. While in secondary forest land and primary forests with a slope of $2-25 \%$ relatively slight erosion.

Land capability class in Koloh Pasiran watershed can be classified into class IV (3 units of land), class V (5 units of land), class VI (1 unit of land) and VIII (2 units of land). The limiting factors are: (e) the slopes are steep and severe erosion rate and (s) low water holding capacity.

Direction of land use for high density mixed garden with bench terrace with good construction, dry with good bench terrace construction and given a booster plants around the lip of land, shrub land used for community forestry, agroporestry and natural forests, while for secondary forests and forest maintained primary sustainability.
\end{abstract}

Keyword: Erosion, Land Capability Classes, Watershed.

\section{PENDAHULUAN}

Kerusakan sumberdaya alam hutan yang terjadi saat ini telah menyebabkan terganggunya keseimbangan lingkungan hidup. Di daerah aliran sungai (DAS) sering terjadi erosi, banjir, kekeringan, pendangkalan sungai, dan waduk serta saluran irigasi. Aktivitas manusia merupakan salah satu penyebab kerusakan sumberdaya alam. Hal ini dapat ditunjukkan dengan adanya perubahan tutupan lahan yang begitu cepat.

Dengan bertambahnya persaingan dalam hal penggunaan lahan di kawasan DAS, maka kerusakan DAS bertambah pula. Oleh karena itu untuk mencegah terjadinya kerusakan DAS lebih lanjut, perlu adanya pengendalian dan penanggulangan dalam bentuk pengelolaan DAS. Pengelolaan DAS merupakan kegiatan untuk memperoleh manfaat produksi dan jasa tanpa menyebabkan terjadinya kerusakan sumberdaya air dan tanah. Hal ini mencakup pengelolaan dan alokasi sumberdaya alam termasuk pencegahan banjir dan erosi serta keterkaitan daerah hulu dan hilir suatu DAS (Asdak, 1995).

Penggunaan lahan yang tepat adalah merupakan langkah utama dalam budidaya tanaman yang baik dan program konservasi tanah dan air yang berhasil. Oleh karena itu, penggunaan lahan atau peruntukan tanah harus sesuai dengan kemampuannya.

Metode USLE (Universal Soil Loss Equation) merupakan metode yang umum dipergunakan untuk memprediksi laju erosi. Wischmeier (1976) dalam Risse et al. (1993) mengatakan bahwa metode USLE didesain untuk digunakan memprediksi kehilangan tanah yang dihasilkan oleh erosi dan diendapkan 
pada segmen lereng bukan pada hulu DAS. Selain itu juga didesain untuk memprediksi rata-rata jumlah erosi dalam waktu yang panjang.

Terjadi kerusakan daerah aliran sungai (DAS) di beberapa daerah di Lombok Timur, karena tidak memperhatikan aspek konservasi tanah dan air serta pentingnya peranan DAS bagian hulu.Peningkatan pemanfaatan sumberdaya alam hutan, tanah dan air dilakukan kadang-kadang tanpa diimbangi dengan usaha-usaha yang menjamin kelestarian sumberdaya alam itu sendiri.

Permasalahan di DAS Koloh Pasiran saat ini adalah adanya masyarakat yang masuk kedalam kawasan hutan untuk melakukan penebangan liar.Lahan di sekitar kawasan hutan sering mengalami kebakaran pada musim kemarau sehingga tanaman yang ada menjadi ikut terbakar dan rusak. sehingga terjadinya degradasi lahan dan lahan menjadi tidak produktif.

Perubahan penutupan lahan akan mempengaruhi besarnya aliran sungai tahunan. Pola perubahan yang umum terjadi adalah bahwa besarnya debit aliran meningkat apabila: (1) jenis vegetasi diganti dari tanaman yang berakar dalam menjadi tanaman berakar dangkal, dan (2) vegetasi penutup tanah diganti dari vegetasi dengan kapasitas intersepsi tinggi ke vegetasi dengan tingkat intersepsi yang lebih rendah (Asdak, 1999).

Mengingat DAS memiliki fungsi hidrologis bagi daerah hilir, maka upaya konservasi tanah pada sistim usaha tani didaerah hulu mutlak harus dilakukan. Di samping itu, kondisi tanah marginal/ kritis tidak akan dapat menunjang pertumbuhan tanaman, tanpa disertai oleh upaya peningkatan kesuburan tanah yang meliputi sifat fisik, kimia, dan biologis tanah.

Penelitian ini ditujukan untuk menentukan tingkat erosi dan perencanaan konservasi tanah dan air di DAS Koloh Pasiran, menentukan kelas kemampuan lahannyadan merencanakan penggunaan lahan berdasarkan kelas kemampuan lahan dan tingkat erosi.

\section{METODE}

\subsection{Ruang Lingkup Penelitian}

Penelitian ini difokuskan pada perencanaan penggunaan lahan, prediksi erosi dan kelas kemampuan lahan.Metode yang dipakai dalam penelitian ini adalah metode survey, pengambilan sampel dilakukan berdasarkan unit lahan yang sudah ditentukan berdasarkan jenis dan penggunaan lahan,kemiringan lereng. Penelitian ini dilakukan di DAS Koloh Pasiran, Kecamatan Sambalia Kabupaten Lombok Timur. Waktu pelaksanaan kegiatan penelitian adalah mulai bulan Februari sampai dengan bulan April 2014. Data yang digunakan dalam penelitian ini adalah data primer dan data sekunder, sedangkan alat dan bahan yang dipergunakan dalam penelitian ini antara lain:kertas tulis, abnelevel. Pisau tanah, bor tanah, meteran, dan ring sample, peta-peta berupa peta liputan tanah, peta topografi, peta kelerengan, peta tanah, peta penggunaan lahan.

\subsection{Prosedur Penelitian}

Pembuatan peta unit lahan dengan cara overlapping (tumpangsusun) peta kelerengan, peta tanah, dan peta penggunaan lahan. Pengertian unit lahan adalah gambaran unsur-unsur lahan yang hampir sama dalam topografi, struktur atau batuan, proses pembentukan kemiringan lereng dan vegetasi (Ditjen RRL, 1998). Pembuatan peta unit lahan dilakukan dengan cara menumpangsusunkan gambar unsur-unsur dan skala yang ada dalam peta haruslah seragam maka didapatkan suatu peta unit lahan.

Pengecekan lapangan dengan melakukan survei pendahuluan, dilaksanakan untuk dapat melakukan persiapan lapangan seperti: mencocokkan letak unit lahan di peta dengan di lapangan, menandai lokasi unit lahan, pada titik dimana akan dilakukan pengamatan dan penelitian.

Survei utama, merupakan kegiatan pengamatan, pengukuran, dan pengambilan sampel tanah pada titik yang telah ditentukan seperti : penggunaan lahan, jenis tanaman, tekstur tanah, struktur tanah, permeabilitas tanah dan bahan organik tanah untuk di analisis di Laboratorium Tanah Fakultas Pertanian Universitas Udayana. Data curah hujan yang digunakan adalah curah hujan rata-rata, jumlah hari hujan bulanan, dan curah hujan maksimum selama $24 \mathrm{jam}$.

Setelah data-data di atas di analisis dan dimasukkan kedalam tabel kreteria klasifikasi kemampuan lahan maka diperoleh penentuan kelas kemampuan lahan selain itu juga dengan menggunakan data-data tersebut di atas digunakan untuk melakukan prediksi erosi, dimana hasil dari prediksi erosi ini akan menjadi dasar untuk pembuatan peta tingkat erosi di DAS Koloh Pasiran.

Dengan adanya data penentuan kelas kemampuan lahan dan prediksi erosi tersebut dapat dijadikan dasar untuk arahan penggunaan lahan di DAS Koloh Pasiran.

\subsection{Analisis Data}

Analisis data sampel tanah dilakukan di Laboratorium Tanah Fakultas Pertanian Universitas Udayana untuk mencapai data fisik dan kimia, selanjutnya data prediksi erosi dihitung dengan rumus USLEserta analisis klasifikasi kemampuan lahan didasarkan atas intensitas faktor penghambat metode Arsyad (1989). 


\section{HASIL DAN PEMBAHASAN}

\subsection{Prediksi Erosi}

\subsubsection{Erosivitas Hujan (R)}

Hasil penghitungan erosivitas hujan pada stasiun pengamatan curah hujan Sambalia selama sembilan tahun (2005-2013) menunjukkan angka sebesar 1217,31 ton/ha/cm. Erosivitas hujan bulanan dari stasiun pencatat curah hujan nilainya bervariasi, yaitu berkisar antara 3,66 sampai 402,8 ton/ha/cm (Tabel 1).

Tabel 1. Erosivitas Hujan (R)di DAS Koloh Pasiran.

\begin{tabular}{lcccc}
\hline Bulan & $\begin{array}{c}\text { Hari Hujan } \\
\text { (hari) }\end{array}$ & $\begin{array}{c}\text { Curah Hujan } \\
\text { (mm) }\end{array}$ & $\begin{array}{c}\text { Curah Hujan } \\
\text { Max (mm) }\end{array}$ & $\begin{array}{c}\text { Erosivitas } \\
\text { Hujan (R) }\end{array}$ \\
\hline Januari & 14 & 302,31 & 117 & 402,8 \\
February & 9 & 176 & 75,56 & 206,7 \\
Maret & 12 & 237,48 & 75,44 & 80,61 \\
April & 7 & 151,44 & 87,89 & 207,2 \\
Mei & 3 & 64,22 & 29,67 & 62,02 \\
Juni & 5 & 73,11 & 24,22 & 51,08 \\
Juli & 1 & 14,67 & 11,56 & 12,36 \\
Agustus & 1 & 7,56 & 7 & 3,66 \\
September & 1 & 32,22 & 25,33 & 41,34 \\
Oktober & 2 & 58,89 & 28,22 & 65,17 \\
Nopember & 4 & 65,11 & 47,33 & 70,01 \\
Desember & 8 & 170,22 & 92,56 & 14,36 \\
\hline Jumlah & 67 & $1.353,23$ & 681,78 & 1217,31 \\
\hline
\end{tabular}

Semakin besar intensitas hujan, maka besar pula partikel tanah yang dilepaskan, karena energi kinetiknya makin besar untuk memecahkan bongkahan-bongkahan tanah menjadi butiran tanah yang kecil-kecil dan halus. Hasil dispersi ini akan lebih mudah terangkut dan terhanyut dengan berlangsungnya aliran permukaan.Sebagian lahan akan mengikuti infiltrasi air, dan bagian ini akan dapat menutupi pori-pori tanah. Tertutupnya poripori tanah menyebabkan menurunnya infiltrasi air kedalam lapisan tanah sehingga lapisan tanah bagian dalam menjdi terhambat sehingga kapasitas infiltrasi menurun. Dengan menurunnya kapasitas infiltrasi akan menyebabkan meningkatnya jumlah aliran permukaan dan daya tekan air pun menjadi kuat sehingga daya erosivitasnya juga semakin besar (Kartasapoetra, dkk 2000).

\subsubsection{Erodibilitas Tanah (K)}

Dari hasil perhitungan menunjukkan bahwa nilai erodibilitas tanah berkisar antara 0,21 sampai $0,62 \mathrm{ton} / \mathrm{ha} / \mathrm{satuan}$ indeks erodibilitas tanah dengan criteria dari sedang sampai sangat tinggi (Tabel 2).

Struktur tanah juga diperkirakan sebagai faktor yang berpengaruh terhadap erodibilitas tanah, kemudian debu, permeabilitas tanah, pasir sangat halus, bahan organik tanah dan liat tanah, tetapi tidak berpengaruh sangat nyata. Hal ini ditujukkan dengan tingkat erodibilitas tanah yang sedang sampai sangat tinggi. Struktur tanah berpengaruh terhadap erodibilitas tanah karena daerah penelitian ini memiliki jenis tanah regosol, andosol dan latosol. Jenis tanah andosol tekstur didominasi oleh pasir, remah bila kering dan daya ikat air yang rendah. Sesuai dengan yang dikatakan oleh Utomo, (1983), tanah jenis andosol, memiliki tekstur yang didominasi oleh debu dan memiliki sifat irreversible terhadap penyerapan air. Jenis latosol bertekstur lempung sampai geluh dan konsistensi gembur peka tererosi (Darmawijaya, 1990).

Syarif (1985) menyebutkan, debu berdiameter relatif kecil, dapat mengadsorpsi air lebih banyak dan persentase pori mikro lebih tinggi dari tanah yang didominasi oleh pasir. Jadi makin halus tekstur tanah, makin tinggi persentase pori mikro dan kemampuan tanah menahan air lebih tinggi. Makin sukar tanah menyerap air, makin jelek struktur tanah makin besar volume limpasan permukaan, makin besar masa tanah terkikis dan terangkut sehingga nilai K juga makin tinggi.

Tabel 2. Nilai Erodibilitas Tanah di DAS Koloh Pasiran.

\begin{tabular}{|c|c|c|c|c|c|c|c|}
\hline \multirow[t]{2}{*}{ No } & \multirow[t]{2}{*}{ Liat (\%) } & \multirow{2}{*}{$\begin{array}{c}\text { Pasir Sangat } \\
\text { Halus + Debu (\%) }\end{array}$} & \multirow{2}{*}{$\begin{array}{c}\text { Bahan } \\
\text { Organik (\%) }\end{array}$} & \multirow{2}{*}{$\begin{array}{l}\text { Kode Struktur } \\
\text { Tanah (b) }\end{array}$} & \multirow{2}{*}{$\begin{array}{l}\text { Kode Permeabilitas } \\
\qquad(\mathrm{cm} / \mathrm{jam})\end{array}$} & \multicolumn{2}{|c|}{ Erodibilitas Tanah ( K) } \\
\hline & & & & & & Nilai & Kreteria \\
\hline 1 & 4,94 & 26,1 & 0,40 & 3 & 1 & 0,21 & Sedang \\
\hline 2 & 14,53 & 54,24 & 0,40 & 3 & 3 & 0,50 & Tinggi \\
\hline 3 & 20,50 & 56,27 & 0,42 & 3 & 6 & 0,56 & Sangat Tinggi \\
\hline 4 & 10,64 & 69,06 & 2,42 & 3 & 5 & 0,62 & Sangat Tinggi \\
\hline 5 & 31,72 & 51,39 & 0,42 & 3 & 4 & 0,40 & Agak Tinggi \\
\hline 6 & 25,97 & 48,11 & 0,43 & 3 & 6 & 0,45 & Tinggi \\
\hline 7 & 24,65 & 43,94 & 1,27 & 3 & 7 & 0,38 & Agak Tinggi \\
\hline 8 & 35,60 & 38,31 & 0,44 & 3 & 6 & 0,33 & Agak Tinggi \\
\hline 9 & 17,14 & 51,1 & 0,45 & 3 & 6 & 0,53 & Tinggi \\
\hline 10 & 8,56 & 26,75 & 0,41 & 3 & 1 & 0,21 & Sedang \\
\hline 11 & 12,72 & 57,02 & 0,47 & 3 & 6 & 0,62 & Sangat Tinggi \\
\hline
\end{tabular}




\subsubsection{Panjang lereng dan Kemiringan Lereng} (LS)

Hasil pengukuran dan pengamatan di wilayah penelitian menunjukkan nilai panjang lereng terpendek sebesar $8 \mathrm{~m}$ dan terpanjang sebesar $60 \mathrm{~m}$. Kemiringan lereng terendah sebesar $2 \%$ sedangkan yang tertinggi sebesar $25 \%$. Nilai LS pada daerah penelitian berkisar antara 0,55 sampai 7,39, dimana nilai LS terendah terdapat pada unit lahan 2 dan tertinggi terdapat pada unit lahan 6 (Tabel 3).

Tabel 3.Nilai Faktor Panjang dan Kemiringan Lereng di DAS Koloh Pasiran.

\begin{tabular}{cccc}
\hline $\begin{array}{c}\text { Unit } \\
\text { Lahan }\end{array}$ & $\begin{array}{c}\text { Panjang } \\
\text { Lereng( L) }\end{array}$ & $\begin{array}{c}\text { Kemiringan } \\
\text { Lereng( S) }\end{array}$ & $\begin{array}{c}\text { Panjang dan Kemiringan } \\
\text { Lereng( LS ) }\end{array}$ \\
\hline 1. & 10 & 2 & 0,62 \\
2. & 8 & 2 & 0,55 \\
3. & 15 & 2 & 0,76 \\
4. & 17 & 3 & 0,96 \\
5. & 40 & 3 & 1,48 \\
6. & 49 & 25 & 7,39 \\
7. & 50 & 5 & 2,19 \\
8. & 52 & 2 & 1,41 \\
9. & 56 & 13 & 4,56 \\
10. & 58 & 4 & 2,07 \\
11. & 60 & 3 & 1,81 \\
\hline
\end{tabular}

Meningkatnya erosi dipengaruhi oleh besarnya faktor kecuraman lereng dan panjang lereng. Semakin curam lereng, maka semakin banyak jumlah tanah yang hilang tererosi oleh air, semakin panjang lereng juga mempengaruhi proses erosi. Erosi secara normal akan meningkat seiring peningkatan panjang dan kecuraman lereng, sebab berpengaruh dalam meningkatnya volume dan kecepatan limpasan permukaan (Morgan, 1979 dalam Mario, 2004).

\subsubsection{Pengelolaan Tanah dan Tanaman (CP)}

Hasil evaluasi penggunaan unit lahan pada kebun campuran dengan kerapatan sedang (nilai faktor $\mathrm{C}=0,2$ ), dengan teras tradisional tanpa adanya konservas (nilai faktor $\mathrm{P}=0,40$ ) dan nilai $\mathrm{CP}=0,08$. Jenis tanaman campuran berupa pisang, mente, kedondong, jati dan gamelia. Tindakan konservasi tanah pada kebun campuran adalah kerapatan lebat $(\mathrm{C}=0,100)$ dengan teras bangku konstruksi baik ( $\mathrm{P}$ $=0,04)($ Tabel 4$)$.

Tegalan dengan pola tanam berurutan dan mulsa sisa tanaman (nilai faktor $\mathrm{C}=0,347$ ) dengan teras tradisional tanpa adanya konservasi (nilai faktor $\mathrm{P}=0,40$ ) dan nilai $\mathrm{CP}=0,1388$. Jenis tanamannya berupa, cabai, tomat, kedelai, bawang merah, jagung. Tindakan konservasi tanah tegalan dengan pola tanam berurutan (jagung, kacang tanah) $\mathrm{C}=0,498$ dengan teras bangku konstruksi baik $\mathrm{P}=$ 0,04 .

Semak belukar, unit lahan ini terdapat pada unit lahan 3 dan 4 dimana penutupan tanahnya adalah semak dan serasah sedang/kurang dengan penutupan tanahnya berupa pohon-pohon (nilai faktor $\mathrm{C}=0,3$ ). Tidak ada tindakan konservasi tanah (nilai faktor $\mathrm{P}=1,00$ ) dan nilai $\mathrm{CP}=0,3$. Jenis tanamannya berupa kayu-kayuan seperti sengon, imba, gamelina, ketimbus. Tindakan konservasi tanah pada unit lahan ini adalah penutupan tanahnya serasah tinggi $(C=0,001)$ dengan teras bangku sempurna $(P=0,04)$.

Hutan sekunder terdapat pada unit lahan 5, dimana hutan ini adalah hutan alam dengan serasah banyak/tinggi dan sudah membusuk (nilai faktor $\mathrm{C}$ $=0,001$ ) dan di unit lahan ini tidak ada konservasi tanahnya (nilai faktor $\mathrm{P}=1,00$ ) dan nilai $\mathrm{CP}=0,001$. Jenis tanamanya berupa pohon-pohon besar sepeti : kesambik, bajur, ketimbus, keleang, temek, berore, reke. Tindakan konservasi tanah yang dilakukan adalah teras koluvial struktur baik $(\mathrm{P}=0,04)$.

Hutan primer terdapat di 6 unit lahan, dimana hutan ini terdapat di hutan tutupan. Hutan primer memiliki serasah yang sangat tinggi dan sudah membusuk kemudian menjadi tanah, hutan ini di tutupi oleh pohon-pohon tinggi (nilai faktor $\mathrm{C}=0,001$ ) dan tidak pernah dilakukan konservasi tanah (nilai

Tabel 4. Nilai Faktor Pengelolaan Tanah dan Tanaman di DAS Koloh Pasiran.

\begin{tabular}{llcccc}
\hline \multirow{2}{*}{$\begin{array}{l}\text { Satuan Unit } \\
\text { No }\end{array}$} & $\begin{array}{c}\text { Jenis Pengelolaan } \\
\text { Tanah dan } \\
\text { Tanaman }\end{array}$ & $\mathbf{C}$ & $\mathbf{P}$ & $\mathbf{C P}$ \\
\cline { 3 - 5 } & & $\mathrm{K} 1$ & 0,2 & 0,40 & $0,08$. \\
1. & Kebun campuran & $\mathrm{T} 1$ & 0,347 & 0,40 & $0,1388$. \\
2. & tegalan & $\mathrm{S} 1$ & 0,3 & 1,00 & 0,3 \\
3. & Semak belukar & $\mathrm{S} 1$ & 0,3 & 1,00 & 0,3 \\
4. & Semak belukar & $\mathrm{H} 0$ & 0,001 & 1,00 & 0,001 \\
5. & Hutan sekunder & $\mathrm{H} 1$ & 0,001 & 1,00 & 0,001 \\
6. & Hutan primer & $\mathrm{H} 1$ & 0,001 & 1,00 & 0,001 \\
7. & Hutan primer & $\mathrm{H} 1$ & 0,001 & 1,00 & 0,001 \\
8. & Hutan primer & $\mathrm{H} 1$ & 0,001 & 1,00 & 0,001 \\
9. & Hutan primer & $\mathrm{H} 1$ & 0,001 & 1,00 & 0,001 \\
10. & Hutan primer & $\mathrm{H} 1$ & 0,001 & 1,00 & 0,001 \\
11. & Hutan primer & & & & \\
\hline
\end{tabular}

Keterangan:

K1 = Kebun campuran dengan kerapatan sedang dengan teras tradisional tanpa adanya konservasi dan Jenis tanaman campuran berupa pisang, kedondong, jati dan gamelia.

T1 = Pertanian lahan kering dengan pola tanam berurutan dan mulsa sisa tanaman dengan teras tradisional tanpa adanya konservasi dan jenis tanamannya berupa padi, cabai, tomat, kedelai, bawang merah, jagung.

S1 = Penutupan tanahnya adalah semak dan serasah sedang/kurang, penutupan tanahnya juga berupa pohon-pohon, tidak ada tindakan konservasi tanah dan jenis tanamannya berupa kayu-kayuan seperti sengon, imba, gamelina, ketimbus.

$\mathrm{HO}=$ Hutan sekunder dalah hutan alam dengan serasah banyak dan sudah membusuk dan di unit lahan ini tidak ada konservasi tanahnya dan jenis tanamanya berupa pohon-pohon besar sepeti : kesambik, bajur, ketimbus, keleang, temek, berore, reke.

$\mathrm{H} 1$ = Hutan primer memiliki serasah yang sangat tinggi dan sudah membusuk kemudian menjadi tanah, hutan ini di tutupi oleh pohon-pohon tinggi dan tidak pernah dilakukan konservasi tanah. Jenis tanamannya berupa: rajumas, suren, goak, kemiri, elar, mangga, kesambik, ketimbus, kendal, sarotan. 
faktor $\mathrm{P}=1,00)$ sehingga nilai $\mathrm{CP}=0,001$. Jenis tanamannya berupa : rajumas, suren, goak, kemiri, elar, mangga, kesambik, ketimbus, kendal, sarotan. Tindakan konservasi tanah pada hutan primer ini adalah teras koluvial struktur baik $(\mathrm{P}=0,04)$

\subsubsection{Prediksi Besarnya Erosi}

DAS Koloh Pasiran memiliki nilai erosi berkisar antara $0,52 \mathrm{t} / \mathrm{ha} /$ thn sampai 217,36 ton/ha/thn yang tergolong ringan sampai sangat berat. Erosi ringan terjadi pada penggunaan lahan kebun campuran, hutan sekunder dan hutan primer karena memiliki nilai CP yang rendah dimana lahannya berupa kebun campuran dengan kerapatan sedang, teras tradisional tanpa konservasi, hutan sekunder dengan serasah banyak sudah mulai membusuk dan tanpa tindakan konservasi sedangkan hutan primer memiliki serasah banyak dan sudah membusuk dan terdapat di unit lahan $6,7,8,9,10$, dan 11 .

Tabel 5. Prediksi Erosi Tahunan di DAS Koloh Pasiran.

\begin{tabular}{lcccccc}
\hline & \multicolumn{4}{c}{ Nilai } & \multicolumn{3}{c}{ Prediksi Erosi ( A ) } \\
\cline { 2 - 7 } No & $\mathbf{R}$ & $\mathbf{K}$ & $\mathbf{L S}$ & $\mathbf{C P}$ & (ton/ha/th) & Tingkat Erosi \\
\hline 1. & 1217,31 & 0,21 & 0,62 & 0,08 & 12,67 & Ringan \\
2. & 1217,31 & 0,50 & 0,556 & 0,1388 & 46,46 & Berat \\
3. & 1217,31 & 0,56 & 0,761 & 0,3 & 155,42 & Berat \\
4. & 1217,31 & 0,62 & 0,968 & 0,3 & 217,36 & Sangat Berat \\
5. & 1217,31 & 0,40 & 1,486 & 0,001 & 0,68 & Ringan \\
6. & 1217,31 & 0,45 & 7,310 & 0,001 & 4,04 & Ringan \\
7. & 1217,31 & 0,38 & 2,197 & 0,001 & 1,01 & Ringan \\
8. & 1217,31 & 0,33 & 1,417 & 0,001 & 0,56 & Ringan \\
9. & 1217,31 & 0,53 & 4,567 & 0,001 & 2,94 & Ringan \\
10. & 1217,31 & 0,21 & 2,078 & 0,001 & 0,52 & Ringan \\
11 & 1217,31 & 0,62 & 1,819 & 0,001 & 1,36 & Ringan \\
\hline
\end{tabular}

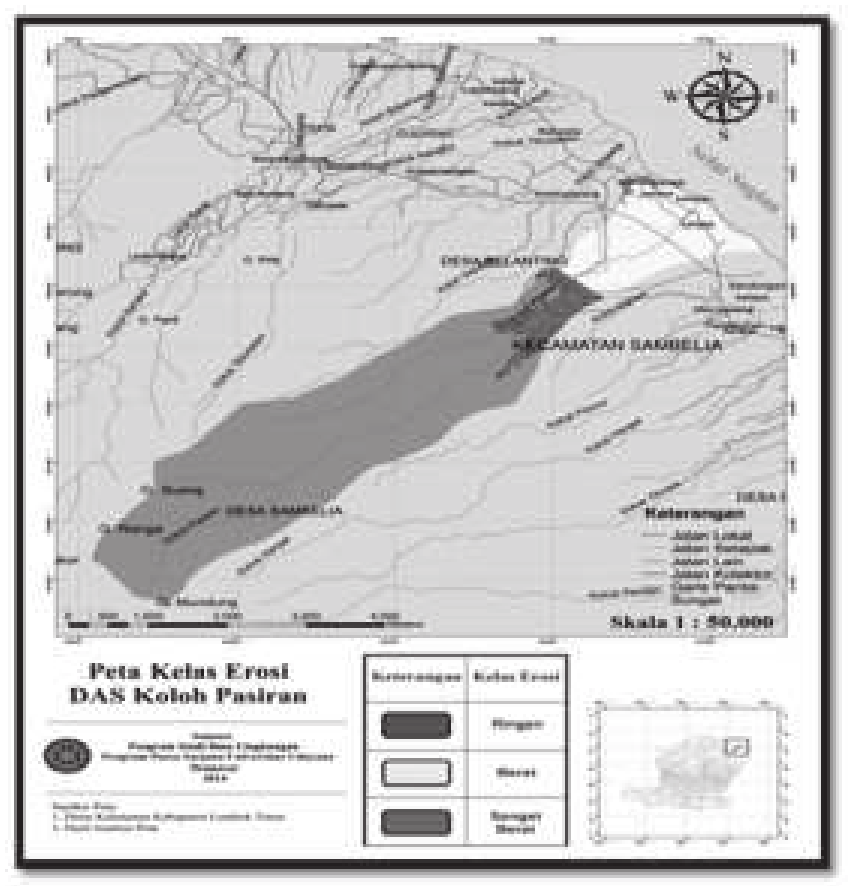

Gambar 1. Peta Kelas Erosi di DAS Koloh Pasiran
Erosi berat sampai sangat berat terjadi pada unit lahan tegalan dan semak belukar. Penyebab berat sampai sangat beratnya erosi yang terjadi pada ketiga unit lahan tersebut disebabkan oleh nilai LS dan CP relatif tinggi, dimana dengan tindakan konservasi yang kurang tepat dengan keadaan lapangan yang teras tradisional mengakibatkan makin tingginya laju erosi pada lahan tersebut.Ringannya erosi yang terjadi pada unit lahan yang lain disebabkan oleh nilai CP yang rendah, karena dengan tajuk tanaman yang cukup rapat jadi butir-butir air hujan yang jatuh akan mengurangi kemampuannya dalam mendispersi tanah sehingga dapat membantu menurunkan laju erosi. CP yang rendah menyebabkan erosi yang terjadi dapat dikurangi

\subsubsection{Erosi yang Ditoleransikan (Edp)}

Untuk menghitung nilai Edp diperlukan data sub-order tanah, kedalaman tanah, dan umur guna tanah dan berat volume tanah. Sub-order tanahnya adalah Tropept dan Ustalf dengan nilai faktor kedalaman tanahnya berkisar antara $550 \mathrm{~mm}$ sampai $770 \mathrm{~mm}$, sedangkan umur guna tanahnya sebesar 300 tahun dan berat volume tanahnya berkisar antara 0,38 sampai 1,588 (Tabel 6). Nilai Edp terendah terdapat pada unit lahan 4 dengan nilai Edp 2,46 ton/ha/thn, sedangkan nilai Edp tertinggi terdapat pada unit lahan 8 dengan nilai Edp 34,46 ton/ha/thn (Tabel 6).

Tabel 6. Erosi yang Dapat Ditoleransikan di DAS Koloh Pasiran.

\begin{tabular}{|c|c|c|c|c|c|c|}
\hline \multirow[t]{2}{*}{ No. } & \multirow[t]{2}{*}{$\begin{array}{l}\text { Unit } \\
\text { Lahan }\end{array}$} & \multicolumn{2}{|c|}{$\begin{array}{c}\text { Fakor Kedalaman } \\
\text { Tanah }\end{array}$} & \multirow{2}{*}{$\begin{array}{l}\text { Umur } \\
\text { Guna } \\
\text { Tanah } \\
\text { (thn) }\end{array}$} & \multirow{2}{*}{$\begin{array}{c}\text { Berat } \\
\text { Volume } \\
\text { Tanah } \\
(\mathrm{g} / \mathrm{cm})\end{array}$} & \multirow{2}{*}{$\begin{array}{c}\text { Erosi yang } \\
\text { ditoleransi }(T) \\
\text { ton/ha/thn }\end{array}$} \\
\hline & & Nilai & $\begin{array}{l}\text { Kedalaman } \\
\text { Tanah }(\mathrm{mm})\end{array}$ & & & \\
\hline 1. & Tropept & 1,00 & 600 & 300 & 0,380 & 7,6 \\
\hline 2. & Tropept & 1,00 & 550 & 300 & 1,326 & 23,87 \\
\hline 3. & Tropept & 1,00 & 600 & 300 & 1,470 & 23,87 \\
\hline 4. & Tropept & 1,00 & 750 & 300 & 0,985 & 2,46 \\
\hline 5. & Tropept & 1,00 & 750 & 300 & 1,094 & 27,35 \\
\hline 6. & Tropept & 1,00 & 700 & 300 & 1,111 & 25,89 \\
\hline 7. & Tropept & 1,00 & 700 & 300 & 1,197 & 27,89 \\
\hline 8. & Tropept & 1,00 & 650 & 300 & 1,588 & 34,46 \\
\hline 9. & Tropept & 1,00 & 700 & 300 & 1,224 & 28,52 \\
\hline 10. & Ustalf & 0,90 & 750 & 300 & 1,237 & 27,83 \\
\hline 11. & Ustalf & 0,90 & 770 & 300 & 0,984 & 22,73 \\
\hline
\end{tabular}

Erosi toleransi berkaitan erat dengan kedalaman efektif tanah dan umur guna tanah, semakin dalam solum tanah, dan semakin tinggi umur guna tanah maka nilai erosi toleransi akan semakin tinggi dan sebaliknya (Arsyad, 1989). Selanjutnya untuk dapat mengendalikan prediksi erosi (A) sama atau lebih kecil dari toleransi (T), diperlukan pemilihan tanaman/pola tanam (C) dan tindakan konservasi tanah (P).Laju erosi yang lebih besar dari erosi yang ditoleransi dijumpai pada unit lahan kebun 
campuran, tegalan dan semak belukar tanpa tindakan konservasi dengan teras tradisional.

\subsubsection{Perencanaan Konservasi Tanah dan Air}

Laju erosi yang lebih kecil dari erosi yang ditoleransi meliputi unit lahan 5, 6, 7, 8, 9, 10 dan 11. Dengan demikian lahan ini tidak memerlukan lagi usaha konservasi tanah dan air akan tetapi harus dipelihara, dijaga dan dipertahankan dengan baik pada kondisi yang sudah ada agar eroai yang terjadi tidak bertambah besar.Prediksi erosi yang melebihi erosi yang ditoleransi dijumpai pada unit lahan kebun campuran dengan nilai $\mathrm{A}=12,67$ ton/ ha/thn, tegalan dengan nilai $\mathrm{A}=46,46 \mathrm{ton} / \mathrm{ha} / \mathrm{thn}$ dan semak belukar dengan nilai $\mathrm{A}=155,42$ dan 217,36 . Ini berarti vegetasi, pola tanam dan tindakan konservasi tanah yang ada belum cukup untuk mencegah atau menekan erosi sampai pada tingkat yang tidak membahayakan.

Untuk mencegah kerusakan tanah sehingga dapat dipergunakan secara lestari, maka nilai A harus ditekan menjadi sama atau lebih kecil dari nilai CP maksimum dengan cara mencari dan menerapkan sistim tanaman atau pola tanam (C) dan tindakan konservasitanah $(\mathrm{P})$ yang sesuai, sedangkan untuk kawasan semak belukar dengan memperhatikan sistim pengolaan tanah yang sesuai (Tabel 7).

Perencanaan konservasi pada unit lahan kebun campuran adalah kebun campurankerapatan lebat dengan jenis tanaman campuran dan teras bangku konstruksi baik. Unit lahan tegalan tanpa tindakan konservasi, alternatif perencanaan konservasi yang dilakukan adalah dengan cara pola tanam yang berurutan seperti cabai, tomat, bawang merah kedelai dan jagung dengan mulsa sisa tanaman dan konservasi teras bangku konstruksi baik, maka erosi yang dapat ditekan menjadi 6,66 ton/ha/thn. Perencanaan pada unit lahan semak belukar dengan serasah sedang, alternatif perencanaan konservasi yang dilakukan adalah hutan dibuat menjadi serasah tinggi tanpa melakukan tindakan konservasi dengan jenis tanaman kayu-kayuan yang sudah ada dan dibuatkan teras bangku konstrukasi baik sehingga dapat menekan erosi menjadi 0,02 ton/ha/thn.

\subsubsection{Besarnya Erosi Setelah Konservasi}

Dari hasil perhitungan besar erosi setelah dikonservasi sebesar 6,74 t/ha/thn untuk unit lahan 2 (tegalan) dengan nilai Edp 23,87 t/ha/thn sedangkan untuk unit lahan 4 (semak belukar) dengan nilai erosi sebesar 0,03 t/ha/thn dengan nilai Edp sebesar 2,46 t/ha/thn (Tabel 8).

Pada unit lahan 2 terdapat sistim tegalan dengan teras tradisional, nilai CP tertinggi yaitu 0,1388 , maka tindakan konservasi yang dilakukan dengan tetap mempertahankan sistim tegalanhanya perbaikan nilai P-nya saja. Adapun alternatif konservasinya yaitu tegalan dengan perbaikan teras bangku konstruksi baik mampu menekan erosi menjadi 6,66 ton/ha/thn.Batas tertinggi nilai CP yang dapat diterapkan pada unit lahan semak belukar adalah hutan dengan serasah tinggi. Perubahan ini dapat menekan nilai erosi sebesar 0,02 ton/ha/thn pada unit lahan semak belukar.

Untuk menurunkan nilai CP maka tindakan konservasi tanah dan air yang dapat dilakukan adalah menambah populasi tanaman ( C ) yang ada saat ini. Apabila nilai (C) diperbaiki maka semak tanpa tindakan konservasi harus ditingkatkan populasi tanamannya atau direboisasikan menjadi hutan serasah tinggi, ini berarti perbaikan nilai (C)

Tabel 7. Alternatif Teknik Konservasi Tanah dan Air di DAS Koloh Pasiran.

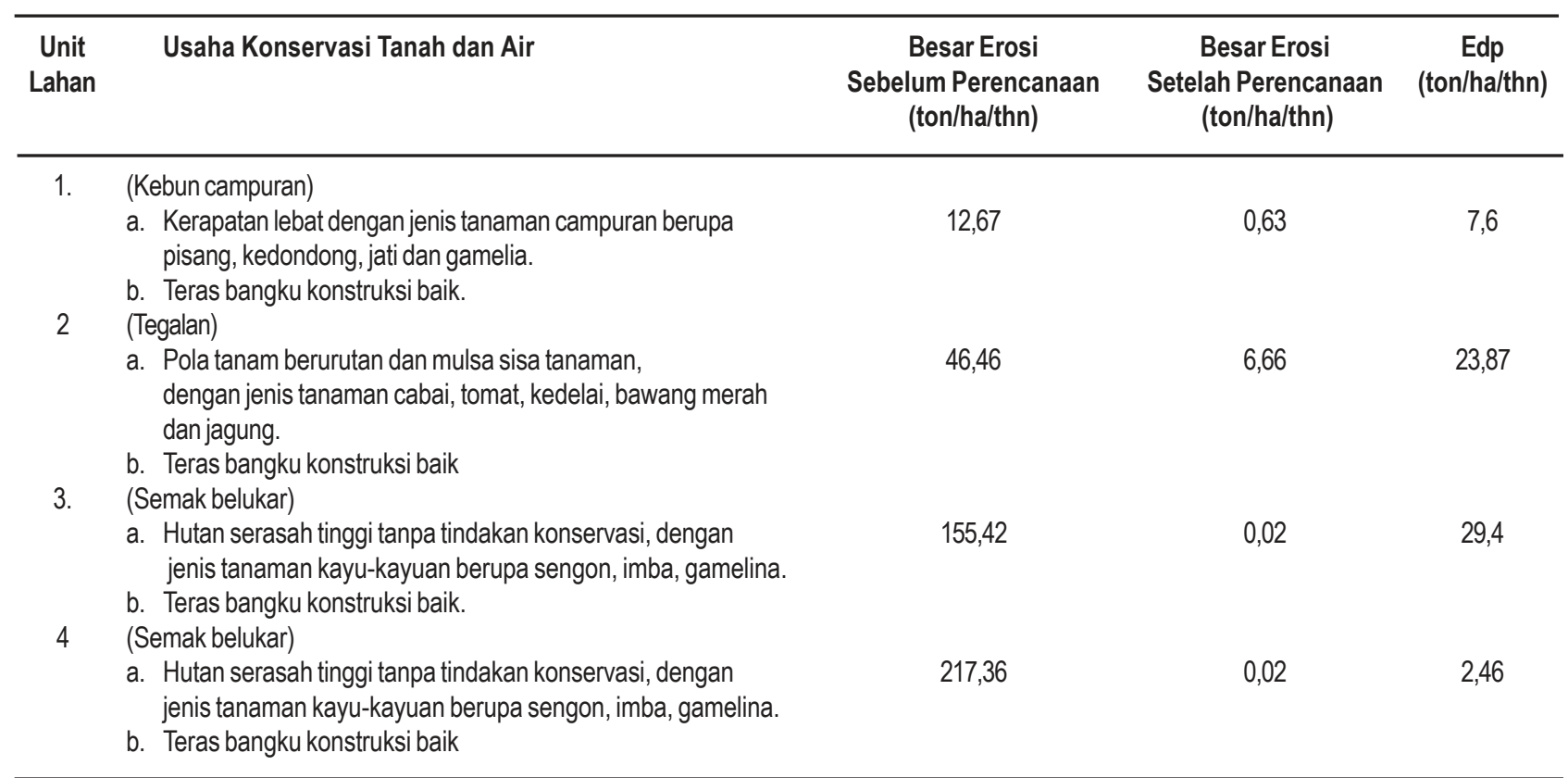


Tabel 8. Alternatif Teknik Konservasi Tanah dan Air di DAS Koloh Pasiran.

\begin{tabular}{lcccccc}
\hline & \multicolumn{4}{c}{ Nilai } & \multicolumn{3}{c}{ Erosi setelah konservasi } \\
\cline { 2 - 7 } & $\mathbf{R}$ & $\mathbf{K}$ & $\mathbf{L S}$ & $\mathbf{C P}$ & (t/ha/th) & Tingkat Erosi \\
\hline 1. & 1217,31 & 0,21 & 0,62 & 0,004 & 0,63 & Ringan \\
2. & 1217,31 & 0,50 & 0,55 & 0,01992 & 6,66 & Sedang \\
3. & 1217,31 & 0,56 & 0,76 & 0,00004 & 0,02 & Ringan \\
4. & 1217,31 & 0,62 & 0,96 & 0,00004 & 0,02 & Ringan \\
5. & 1217,31 & 0,40 & 1,48 & 0,00004 & 0,02 & Ringan \\
6. & 1217,31 & 0,45 & 7,39 & 0,00004 & 0,16 & Ringan \\
7. & 1217,31 & 0,38 & 2,19 & 0,00004 & 0,04 & Ringan \\
8. & 1217,31 & 0,33 & 1,41 & 0,00004 & 0,02 & Ringan \\
9. & 1217,31 & 0,53 & 4,56 & 0,00004 & 0,11 & Ringan \\
10. & 1217,31 & 0,21 & 2,07 & 0,00004 & 0,02 & Ringan \\
11 & 1217,31 & 0,62 & 1,81 & 0,00004 & 0,05 & Ringan \\
\hline
\end{tabular}

saja pada unit lahan tersebut sudah memiliki nilai $\mathrm{CP}$ yang rendah dari nilai CP tertinggi yang ditetapkan.

\subsection{Klasifikasi Kemampuan Lahan DAS Koloh Pasiran}

Hasil evaluasi klasifikasi kemampuan lahan pada daerah penelitian menunjukkan kelas IV dan sub kelas IV es terdapat di 3 (tiga) unit lahan yaitu 4, 5 dan 7; kelas $\mathrm{V}$ dan sub kelas $\mathrm{V}$ es terdapat di 5 (lima) unit lahan yaitu 3, 6, 8, 9 dan 11; kelas VI dan sub kelas VI es terdapat pada unit lahan 2; sedangkan kelas VIII dengan sub kelas VIII s dan VIII es terdapat di 2 (dua) unit lahan yaitu 1 dan 10 (Tabel 9).

Faktor pembatas yang diperoleh pada daerah penelitian adalah sub kelas (e) menunjukkan ancaman erosi atau tingkat erosi yang telah terjadi merupakan masalah utama, karena kecuraman lereng dan kepekaan erosi tanah, dan sub kelas (s) menunjukkan bahwa tanah mempunyai hambatan daerah perakaran seperti kedalaman tanah dangkal atau lapisan yang menghambat perkembangan akar dan adanya batuan dipermukaan tanah serta salinitas yang menghambat pertumbuhan tanaman (Arsyad, 1989).

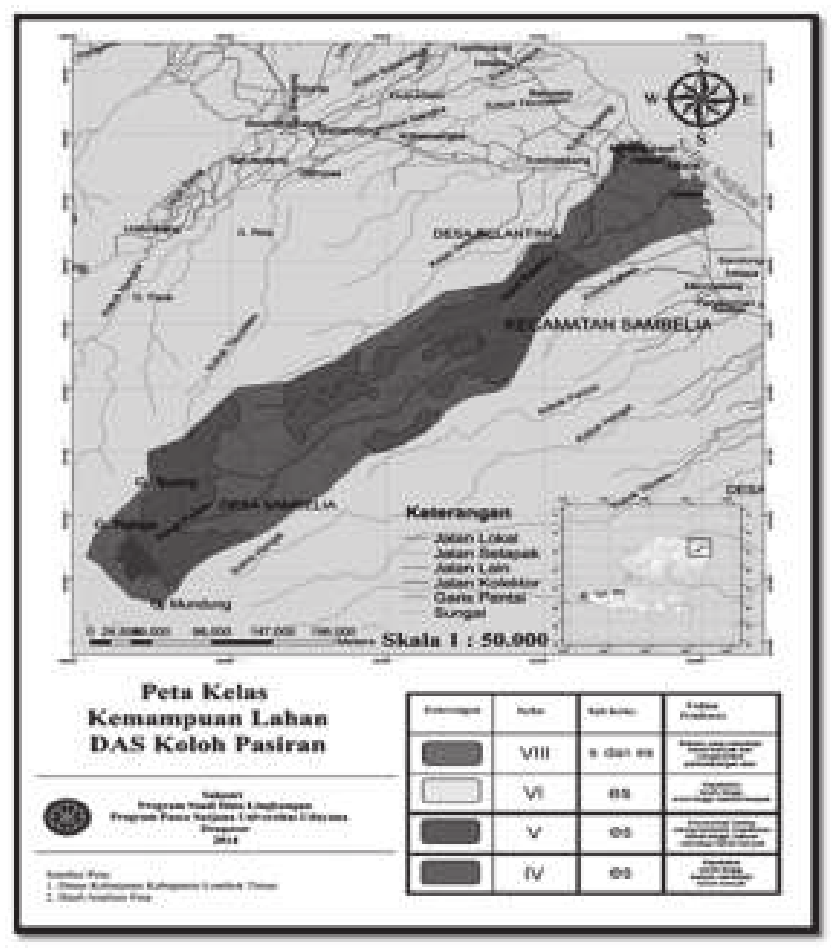

Gambar 2. Peta Kelas Kemampuan Lahan di DAS Koloh Pasiran

\subsection{Arahan Penggunaan Lahan}

Berdasarkan hasil kelas kemampuan lahan, prediksi erosi dan data erosi yang dapat toleransikan dapat direncanakan alternatif penggunaan lahan pada DAS Koloh Pasiran (Tabel 10).

Unit lahan pada kebun campuran dengan kemiringan lahan datar, sub kelas VIIIs dengan tingkat erosi ringan. Bisa dijadikan sebagai perkebunan campuran dengan kerapatan tinggi, serta penerapan teknik konservasi tanah dan air. Melihat kondisi di lapangan, penggunaan lahan pada kebun campuran, maka untuk mengurangi ancaman erosi yang terjadi dan meningkatkan kapasitas menahan air, diperlukan pengelolaan sebagai kebun

Tabel 9. Kelas Kemampuan Lahan di DAS Koloh Pasiran.

\begin{tabular}{|c|c|c|c|c|c|c|c|c|c|c|c|c|}
\hline No & $\begin{array}{c}\text { Lereng } \\
\text { permukaan }\end{array}$ & Kepekaan & $\begin{array}{l}\text { Tingkat } \\
\text { Erosi }\end{array}$ & $\begin{array}{l}\text { Kedalaman } \\
\text { Tanah }\end{array}$ & $\begin{array}{c}\text { Tekstur } \\
\text { lapisan atas }\end{array}$ & $\begin{array}{l}\text { Permea- } \\
\text { bilitas }\end{array}$ & Drainase & Krikil & $\begin{array}{c}\text { Ancaman } \\
\text { Banjir }\end{array}$ & $\begin{array}{l}\text { Garam/ } \\
\text { salinitas }\end{array}$ & kelas & Sub kelas \\
\hline 1. & A & $\mathrm{KE}_{3}$ & e1 & $\mathrm{k}_{1}$ & $t_{5}$ & P5 & $d_{1}$ & $b_{2}$ & $\mathrm{O}_{0}$ & $g_{0}$ & VIII & VIII s \\
\hline 2. & $A$ & $\mathrm{KE}_{5}^{3}$ & $e_{4}$ & $\mathrm{~K}_{1}$ & $t_{3}^{5}$ & P4 & $d_{1}$ & $b_{2}^{2}$ & $\mathrm{O}_{0}$ & $g_{1}$ & VI & VI es \\
\hline 3. & $A$ & $\mathrm{kE}_{6}^{5}$ & $e_{2}^{4}$ & $\mathrm{~K}_{1}^{1}$ & $t_{3}^{3}$ & P1 & $d_{1}$ & $b_{2}^{2}$ & $\mathrm{O}_{0}$ & $g_{0}$ & V & Ves \\
\hline 4. & $A$ & $\mathrm{KE}_{6}^{\circ}$ & $e_{1}$ & $\mathrm{~K}_{1}$ & $t_{3}$ & P2 & $\mathrm{d}_{1}$ & $b_{2}$ & $\mathrm{O}_{0}$ & $g_{1}$ & IV & IV es \\
\hline 5. & $A$ & $\mathrm{kE}_{4}$ & $e_{2}$ & $\mathrm{~K}_{1}$ & $t_{2}$ & P3 & $d_{2}$ & $b_{2}$ & $\mathrm{O}_{0}$ & $g_{0}$ & IV & IV es \\
\hline 6. & $D$ & $\mathrm{KE}_{5}$ & $\mathrm{e}_{2}$ & $\mathrm{~K}_{1}^{1}$ & $t_{3}^{2}$ & P1 & $d_{2}^{2}$ & $b_{2}^{2}$ & $\mathrm{O}_{0}$ & $g_{1}$ & V & V es \\
\hline 7. & B & $\mathrm{KE}_{4}$ & $e_{2}$ & $K_{1}^{\prime}$ & is & P2 & $d_{1}^{2}$ & $b_{2}^{2}$ & $\mathrm{O}_{0}$ & $g_{3}$ & IV & IV es \\
\hline 8. & $A$ & $\mathrm{KE}_{4}^{4}$ & $\mathrm{e}_{2}$ & $\mathrm{~K}_{1}^{\top}$ & $t_{2}$ & P1 & $d_{1}$ & $b_{2}^{2}$ & $\mathrm{O}_{0}$ & $g_{3}$ & V & V es \\
\hline 9. & C & KE6 & $\mathrm{e}^{2}$ & $\mathrm{~K}_{1}^{1}$ & $t_{3}^{2}$ & P1 & $d_{1}$ & $b_{2}^{2}$ & $\mathrm{O}_{0}$ & $g_{0}$ & V & V es \\
\hline 10. & B & $\mathrm{KE}_{3}$ & $\mathrm{e}_{2}$ & $\mathrm{~K}_{1}$ & $t_{4}$ & P5 & $d_{1}$ & $b_{2}$ & $\mathrm{O}_{0}$ & $g_{1}$ & VIII & VIII es \\
\hline 11. & $A$ & $\mathrm{KE}_{6}^{0}$ & $\mathrm{e}_{2}$ & $K_{1}^{\prime}$ & $t_{3}^{4}$ & P1 & $d_{1}$ & $b_{2}$ & $\mathrm{O}_{0}$ & $g_{1}$ & V & Ves \\
\hline
\end{tabular}


Tabel 10. Kelas Kemampuan Lahan di DAS Koloh Pasiran.

\begin{tabular}{|c|c|c|c|c|}
\hline $\begin{array}{l}\text { Unit } \\
\text { Lahan }\end{array}$ & $\begin{array}{l}\text { Sub Kelas } \\
\text { Kemampuan } \\
\text { Lahan }\end{array}$ & $\begin{array}{l}\text { Penggunaan } \\
\text { Lahan } \\
\text { Sebelumnya }\end{array}$ & $\begin{array}{l}\text { Arahan Penggunaan } \\
\text { Lahan }\end{array}$ & Rencana Penggunaan Lahan \\
\hline 1. & VIII s & Kebun campuran & $\begin{array}{l}\text { Perkebunan campuran } \\
\text { dengan kerapatan tinggi }\end{array}$ & $\begin{array}{l}\text { Kebun campuran dengan kerapatan tinggi dan penerapan teknik konservasi } \\
\text { tanah antara lain penanaman secara kontur, perbaikan konstruksi teras } \\
\text { disertai tanaman penutup tanah dan penggunaan mulsa dengan jumlah } \\
\text { banyak. }\end{array}$ \\
\hline 2. & VI es & Tegalan & $\begin{array}{l}\text { Tegalan dengan teras } \\
\text { bangku konstruksi baik }\end{array}$ & $\begin{array}{l}\text { Jenis tanaman seperti, jagung, kacang-kacangan, bawang merah dengan } \\
\text { tindakan konservasi pemberian mulsa sisa tanaman dan pembuatan teras } \\
\text { konstruksi baik dan diberi tanaman penguat. }\end{array}$ \\
\hline 3. & Ves & Semak Belukar & $\begin{array}{l}\text { Hutan kemasyarakatan, } \\
\text { dan hutan lindung } \\
\text { (Dihutankan) }\end{array}$ & $\begin{array}{l}\text { Hutan kemasyarakatan, agroforestry atau dijadikan hutan } \\
\text { alami dengan jenis tanaman kayu-kayuan. }\end{array}$ \\
\hline 4. & IV es & Semak Belukar & Dihutankan & Dijadikan hutan alami dengan jenis tanaman kayu-kayuan. \\
\hline 5. & IV es & Hutan Sekunder & hutan alami & Hutan alami \\
\hline 6. & Ves & Hutan Primer & hutan alami & Hutan alami \\
\hline 7. & IV es & Hutan Primer & hutan alami & Hutan alami \\
\hline 8. & Ves & Hutan Primer & hutan alami & Hutan alami \\
\hline 9. & Ves & Hutan Primer & hutan alami & Hutan alami \\
\hline 10. & VIII es & Hutan Primer & hutan alami & Hutan alami \\
\hline 11. & Ves & Hutan Primer & hutan alami & Hutan alami \\
\hline
\end{tabular}

campuran dengan kerapatan tinggi, penerapan teknik konservasi tanah yang memadai dengan cara penanaman sejajar kontur, penanaman penutup tanah dan penggunaan mulsa sisa tanaman.

Hasil perencanaan pada penggunaan lahan tegalan dengan lereng permukaan datar dan tingkat erosi berat dapat digunakan alternatif sebagai berikut: untuk kawasan ini arahan penggunaan lahannya adalah tegalan dengan teras bangku konstruksi baik, pada umumnya penggunaan lahannya berupa pertanian lahan kering sehingga dalam pengelolaannya dapat ditanami jagung, kacang-kacangan, bawang merah dan sisa tanaman dapat digunakan sebagai mulsa. Pengelolaan lainnya yang dapat diterapkan antara lain penanaman tanaman yang dapat memperkuat daya tahan tanah seperti lamtorogung, kaliandra, gamal, akasia dan pemberian mulsa yang bertujuan untuk pengawetan tanah dan air, pengendalian erosi serta meningkatkan produktifitasnya. Pada unit lahan semak belukar (3 dan 4) lereng permukaan datar dengan tingkat erosi ringan dapat dilakukan alternatif arahan penggunaan lahannya berupa hutan kemasyarakatan atau hutan lindung. Dalam pengelolaan lahannya dapat dijadikah hutan kemasyarakatan, agroforestry dan hutan alamai dengan jenis tanaman kayu-kayuan. Pada unit lahan $5,6,7,8,9,10$, dan 11 dibiarkan menjadi hutan alami dimana penutupan tanahnya berupa pohon kayu-kayuan dan semak, pengunaan lahannya dibiarkan menjadi hutan alami tanpa adanya konservasi.

\section{SIMPULAN DAN SARAN}

\subsection{Simpulan}

1. Nilai erosi di DAS Koloh Pasiran berkisar antara 0,52 sampai 217,36 ton/ha/thn yang tergolong ringan sampai sangat berat. Erosi ringan terjadi pada unit lahan kebun campuran, hutan primer dan hutan sekunder sedangkan erosi berat sampai sangat berat terjadi pada unit lahan tegalan dan semak belukar.

2. Kelas kemampuan lahan DAS Koloh Pasiran dapat digolongkan kedalam kelas IV sampai kelas VIII. Kelas IV terdapat pada unit lahan 4, 5 dan 7; kelas $\mathrm{V}$ terdapat pada unit lahan 3, 6, 8, 9 dan 11; kelas VI terdapat pada unit lahan 2 dan kelas VIII terdapat pada unit lahan 1 dan 10, dengan faktor pembatasnya adalah (e) ancaman erosi dan (s) kapasitas menahan air rendah.Tanah dengan kelas kemampuan lahan IV tidak sesuai untuk digunakan bagi usaha tani tanaman semusim, tetapi karena unit lahan kelas IV berada di wilayah semak belukar dan hutan primer maka sebaiknya dihutankan atau vegetasi permanen. Tanah pada kelas $\mathrm{V}$ tidak cocok untuk usaha tani tanaman semusim karena terdapat pada kawasan semak dan hutan sebaiknya di hutankan. Unit lahan pada kelas VItidak sesuai untuk tanaman semusim tetapi karena berada di lahan tegalan maka digarap untuk usaha tanaman semusim, seperti jagung, kacang-kacangan atau vegetasi permanen. Unit lahan kelas VIII tidak sesuai untuk 
pertanian tanaman semusim tetapi lebih cocok untuk tanaman kayu dan buah-buahan seperti mente, kedondong jati dan gamelia karena berada di lahan kebun campuran, sedangkan unit lahan yang terdapat di hutan primer harus dibiarkan pada keadaan alami di bawah vegetasi alami

3. Arahan penggunaan lahan pada unit lahan kebun campuran yaitu kebunan campuran dengan kerapatan tinggi. Unit lahan tegalan dengan teras bangku konstruksi baik. Unit lahan semak belukar arahan pengunaan lahannya berupa hutan kemasyarakatan atau hutan lindung. Sedangkan untuk kawasan hutan dibiarkan menjadi hutan alami.

\subsection{Saran}

Untuk mengurangi besarnya laju erosi perlu memperhatikan pengelolaan tanah yang sesuai dengan menerapkan tehnik konservasi tanah dan air serta memperhatikan kelas kemampuan lahan yang ada sehingga pemanfaatan lahan yang melebihi kapasitasnya (berlebihan) dapat ditekan.

Upaya pengelolaan yang perlu dilakukan pada unit lahan perkebunan campuran dengan kerapatan tinggi dan tegalan dengan teras bangku sempurna adalah penanaman tanaman jenis kayu-kayuan dan buah-buahan seperti mente, mangga dan pisang sedangkan pada tegalan jenis tanaman berupa jagung, bawang merah dan kacang-kacangan dengan pemulsaan sehingga dapat meningkatkan kapasitas menahan air.

\section{DAFTAR PUSTAKA}

Arsyad, S. 1989. Konservasi Tanah dan Air.Institut Pertanian Bogor.

Asdak, C. 1995. Hidrologi dan Pengelolaan Daerah Aliran Sungai.Yogyakarta. Gajah Mada University Press.
Darmawijaya, M.I. 1990. Klasifikasi Tanah . Cetakan Pertama. Yogyakarta : Gajah Mada University Press.

Direktorat Jendral Reboisasi dan Rehabilitasi Lahan (Ditjen RRL). 1998. Petunjuk Pelaksanaan Penyusunan Rencana Teknik Lapangan Rehabilitasi Lahan dan Konservasi Tanah. Departemen Kehutanan. Jakarta.

Kartasapoetra, G., A. G. Kartasapoetra, dan M.M. Sutejo. 2000. Teknologi Konservasi Tanah dan Air. Edisi Kelima. Penerbit Rineka Cipta. Jakarta.

Mario, K, 2004. "Arahan Penggunaan Lahan di DAS Banyumala Buleleng Bali”. (tesis). Program Studi Magister Lahan Kering, Program Pascasarjana, Universitas Udayana. Denpasar.

Morgan, R.P.C. 1979. Soil Erosion. London : Longman

Risse, L.M.,M.A Nearing, A.D. Nicks, and J.M. Laflen. 1993. Error Assessment in the Universal Soil Loss Equation. Soil. Sci. Soc. Am. J. Vol. 57 : 825-833.

Sanders, D. 1992. Soil Conservation Asia.An Interpretation perspective Journal of Soil and Water Conservation, 5 (3): $45-60$.

Syarief, S. E.1985. Konservasi Tanah dan Air. Pustaka Buana, Bandung.

Utomo, Wani Hadi. 1989. Konservasi Tanah di Indonesia. Suatu Rekaman Analisa Rajawali Press. Jakarta. 176 hal.

Wischmeier, W. H. and D.D Smith.1978.Pedicting Rainfall Erosion Losses - A Guide To Conservation Planning USDA Agricultural Handbook No. 537.59 pp. 